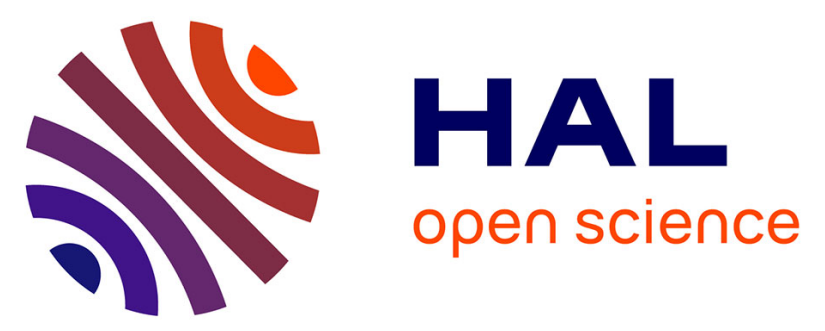

\title{
Hypertensive disorders of pregnancy and gestational diabetes mellitus among French Caribbean women chronically exposed to chlordecone.
}

Lauren Saunders, Philippe Kadhel, Nathalie Costet, Florence Rouget, Christine Monfort, Jean-Pierre Thomé, Laurence Guldner, Sylvaine Cordier, Luc Multigner

\section{To cite this version:}

Lauren Saunders, Philippe Kadhel, Nathalie Costet, Florence Rouget, Christine Monfort, et al.. Hypertensive disorders of pregnancy and gestational diabetes mellitus among French Caribbean women chronically exposed to chlordecone.. Environment International, 2014, 68, pp.171-6. 10.1016/j.envint.2014.03.024 . hal-01061391

\section{HAL Id: hal-01061391}

\section{https://hal-univ-rennes1.archives-ouvertes.fr/hal-01061391}

Submitted on 5 Sep 2014

HAL is a multi-disciplinary open access archive for the deposit and dissemination of scientific research documents, whether they are published or not. The documents may come from teaching and research institutions in France or abroad, or from public or private research centers.
L'archive ouverte pluridisciplinaire HAL, est destinée au dépôt et à la diffusion de documents scientifiques de niveau recherche, publiés ou non, émanant des établissements d'enseignement et de recherche français ou étrangers, des laboratoires publics ou privés. 
Hypertensive disorders of pregnancy and gestational diabetes mellitus among French Caribbean women chronically exposed to chlordecone.

Lauren Saunders ${ }^{\mathrm{a}}$, Philippe Kadhel ${ }^{\mathrm{a}, \mathrm{b}}$, Nathalie Costet ${ }^{\mathrm{a}}$, Florence Rouget ${ }^{\mathrm{a}}$, Christine Monfort ${ }^{\mathrm{a}}$, Jean-Pierre Thomé ${ }^{\mathrm{c}}$, Laurence Guldner ${ }^{\mathrm{d}}$, Sylvaine Cordier ${ }^{\mathrm{a},{ }^{\dagger}}$ and Luc Multigner $\mathrm{a},{ }^{*}, \dagger$

a Team of Epidemiological Research on Environment, Reproduction and Development, National Institute for Health and Medical Research (INSERM U1085), Rennes, France;

b Gynecology and Obstetric Unit, CHU Pointe à Pitre/Abymes, Guadeloupe, French West Indies;

${ }^{\mathbf{c}}$ Center for Analytical Research and Technology, Liege University, Belgium;

${ }^{\text {d }}$ French Institute for Public Health Surveillance (InVS), Department of Environmental Health, St-Maurice, France

* Corresponding author:

Email address: luc.multigner@inserm.fr

Address correspondence :INSERM, UMR1085, IRSET, Faculté de Médecine, Campus de Fouillole, BP145, 97154 Pointe à Pitre Cedex, Guadeloupe, French West Indies.

Tel. : + 590690730282

$\uparrow$ Equal contribution

Abbreviations: GH, gestational hypertension; PE, preeclampsia; GDM, gestational diabetes mellitus; OC, organochlorine; DDE, p,p'-dichlorodiphenyldichloroethylène; PCB, polychlorinated biphenyl; LOD, limit of detection; OR, odds ratio; CI, confidence interval. 


\begin{abstract}
Few studies have explored the consequences of environmental exposure to organochlorine pesticides for gestational hypertension $(\mathrm{GH})$, preeclampsia (PE) and gestational diabetes mellitus (GDM). Chlordecone is a persistent organochlorine pesticide that was used intensively, and almost exclusively, in the French West Indies until 1993. We investigated the impact of prenatal exposure to chlordecone on the occurrence of GDM, GH and PE by studying 779 pregnant women enrolled in a prospective mother-child cohort (Timoun study) in Guadeloupe between 2004 and 2007. Chlordecone exposure was determined by assaying maternal plasma and information about pregnancy complications was obtained from midwives, pediatricians and hospital medical records after delivery. The risks of GH $(n=65)$, PE $(n=31)$ and GDM $(n=71)$ were estimated by multiple logistic regression including potential confounders. Levels of chlordecone plasma concentration in the third $(\mathrm{OR}=0.2$; $95 \%$ confidence interval $(\mathrm{CI}): 0.1,0.5)$ and fourth quartiles $(\mathrm{OR}=0.3 ; 95 \% \mathrm{CI}: 0.2,0.7)$ were associated with a statistically significant decrease in the risk of GH. A $\log 10$ increase in chlordecone concentration was significantly associated with lower risk of $\mathrm{GH}(\mathrm{OR}=0.4$; 95\% CI: $0.2,0.6)$. No significant associations were observed between chlordecone exposure and the risk of PE or GDM. This study suggests an inverse association between chlordecone exposure during pregnancy and GH. Further studies are required to determine the underlying mechanism, or the potential unknown confounding factors, resulting in this association.
\end{abstract}

Key words: Chlordecone; Endocrine disruptor; Gestational diabetes; Gestational hypertension; Organochlorine pesticides; Preeclampsia 


\section{Introduction}

Hypertensive disorders and diabetes mellitus are common problems a woman may experience during pregnancy (Olsen and Basso, 2005). These pregnancy complications are associated with significant short-term and long-term adverse health outcomes for both mothers and offspring.

Hypertensive disorders occur in 6\% to $8 \%$ of pregnancies (National High Blood Pressure Education Program, 2000). They include gestational hypertension (GH) and preeclampsia (PE). Gestational hypertension describes women who develop hypertension after 20 weeks of gestation without proteinuria (Leeman and Fontaine, 2008). In most cases, it does not compromise the pregnancy but may be a precursor sign of later chronic hypertension or lead to worse perinatal outcomes if the woman progresses to severe GH (defined as a substantial increase in blood pressure). The causes of most cases of GH remain unknown. Preeclampsia is a pregnancy-specific syndrome characterized by increased blood pressure accompanied by proteinuria. Is a major cause of maternal mortality and morbidity, perinatal death, preterm birth, and intrauterine growth restriction (Sibai et al., 2005).

The prevalence of gestational diabetes mellitus (GDM) may range from $1 \%$ to $14 \%$ of all pregnancies, depending on the population studied and the diagnostic test employed (American Diabetes Association, 2004). Overweight or obesity and ethnicity are recognized risk factors (Zhang and Ning, 2011). Women with GDM are at increased risk of perinatal morbidity, impaired glucose tolerance and type 2 diabetes in the years after pregnancy. Children of women with GDM are also more likely to be obese and have impaired glucose tolerance and diabetes in childhood and early adulthood (Zhang and Ning, 2011).

Several studies have investigated risk factors for the occurrence of these pregnancy complications. However, few have examined the contribution of environmental risk factors 
such as pesticides, and in particular persistent organochlorine pesticides (OC). Recent reports from the Agricultural Health Study show an increased risk of self-reported GH, PE and GDM associated with residential or agricultural pesticide exposure during the first trimester of pregnancy (Saldana et al., 2007, 2009). In a recent population-based cohort in the Netherlands, no consistent associations between occupational exposure to chemicals, including pesticides, during pregnancy and hypertensive disorders were observed, but the frequency of exposure to chemicals in general and to pesticides in particular was very low (Nugteren et al., 2012). In a large cohort study of exposures of Norwegian farmers to immunomodulating substances, pesticide use was found to be associated with a moderate, but statistically significant, decrease in the risk of PE (Nordby et al., 2006).

For OC exposure during pregnancy, an inverse association between exposure to p,p'dichlorodiphenyldichloroethylene (DDE), the main metabolite of dichlorodiphenyl trichloroethane, or to PCBs and GH and PE was identified by a large birth cohort study including 2,193 women (Savitz et al., 2013). In the general population, contradictory results have been found concerning exposure to OC pesticides and hypertension risk (Goncharov et al., 2011; Ha et al., 2009; Valera et al., 2013a, 2013b). We have been unable to find any study of the relationship between exposure to OC pesticides and GDM. Studies in the general population suggest that altered glucose metabolism, increased insulin resistance and reduced insulin production related to OC pesticide exposure may contribute to causing diabetes (Lee et al., 2006; Montgomery et al., 2008; Rylander et al., 2005).

The present study focuses on the population of Guadeloupe (French West Indies), which has been chronically exposed to chlordecone. Chlordecone is almost the only OC pesticide that was used, and extensively, in French West Indies to control banana root borers between the early 1970s and 1993. Chlordecone undergoes no significant biotic or abiotic degradation in the environment (Cabidoche et al., 2009; Faroon et al., 1995). As a consequence and 
despite chlordecone prohibition in 1993, permanently polluted soils and waterways have been, and are still nowadays, the major sources of human contamination in French West Indies, through the consumption of contaminated and locally produced foodstuffs (Dubuisson et al., 2007; Guldner et al., 2010).

Studies on animals have documented that pre-gestational or gestational exposure of rats and mice to chlordecone affects embryo implantation and both prenatal and postnatal development (Faroon et al., 1995). The mechanism of the toxic action of chlordecone is not completely understood but it has been suspected that its hormonal properties and/or its effect on neurotransmission may be involved (Faroon et al., 1995).

Experimental studies have documented the toxic effects of chlordecone exposure during gestation in animals, but there has been no epidemiological study to determine if chlordecone has similar consequences in humans at environmentally relevant exposure levels. The Timoun mother-child cohort study was established to investigate the consequences for pregnancy and child development of prenatal exposure to the widespread chlordecone pollution in the French West Indies. We recently reported an association between maternal exposure to chlordecone during pregnancy and an increased risk of preterm birth (Kadhel et al., 2014). Here, we report the relationships between maternal exposure to chlordecone and the risk of GH, PE and GDM.

\section{Methods}

\subsection{Population and study design}

The study population consisted of pregnant women enrolled in the Guadeloupean prospective epidemiological mother-child cohort study, Timoun, from November 2004 to December 2007. Women who had been living in Guadeloupe for at least 3 years were enrolled during the third-trimester prenatal visit to a Guadeloupe public hospital or 
dispensary. Of the 1,068 women participants, we excluded women whose pregnancy ended in medical termination, fetal death or stillbirth $(n=6)$, women whose babies had major congenital malformations according to the EUROCAT definitions (EUROCAT, 2005) $(n=36)$, and women with missing data on pregnancy complications $(n=34)$ or on chlordecone exposure measurements $(\mathrm{n}=213)$. The final analysis included 779 pregnant women. The study was approved by the Guadeloupean Ethics Committee for studies involving human subjects and each participant provided written informed consent.

\subsection{Exposure assessment}

The chlordecone concentration in maternal blood samples collected into EDTA tubes during labor was determined. After centrifugation, the resulting plasma samples were transferred to polypropylene $\mathrm{Nunc}^{\circledR}$ tubes and stored at $-30^{\circ} \mathrm{C}$. Plasma samples were transferred, in dry ice, to the Center for Analytical Research and Technology (Liège, Belgium) for determination of chlordecone concentrations by gas chromatography-electron capture detection. Preparation of samples and the quantification method were as previously described (Debier et al., 2003: Multigner et al., 2010), and details including quality control data are provided in Supplemental material. The limit of detection (LOD) of chlordecone was $0.06 \mu \mathrm{g} / \mathrm{L}$. Samples from a subgroup of 358 women were also assayed for DDE and PCB 153 (Debier et al., 2003). The LOD for both compounds were $0.05 \mu \mathrm{g} / \mathrm{L}$. Total cholesterol and triglyceride concentrations in plasma were determined by standard enzymatic procedures (DiaSys Diagnostic Systems GmbH, Holzheim, Germany) and total lipid concentrations were calculated as described elsewhere (Bernet et al., 2007)

\subsection{Pregnancy complications}

Information about the medical history of the pregnancy was collected from midwives, pediatricians and hospital medical records after delivery. Participants were considered to have GH if they developed systolic blood pressure $\geq 140 \mathrm{~mm} \mathrm{Hg}$ and/or diastolic blood pressure $\geq$ 
$90 \mathrm{~mm} \mathrm{Hg}$ after 20 weeks of gestation without proteinuria and if they were previously normotensive. PE was defined as $\mathrm{GH}$ associated with proteinuria $\geq 0.3 \mathrm{~g} / \mathrm{L}$ in a 24-hour urine sample (National High Blood Pressure Education Program, 2000). Women who were diagnosed with both $\mathrm{GH}$ and PE were assigned to the PE group. Women assigned to the GH group had GH alone. If hypertension was reported before pregnancy and/or it was detected before 20 weeks of gestation, the women were considered to have chronic hypertension and were included in the control group. Women were considered to have GDM if they had two or more abnormal glucose tolerance test results between 24 and 28 weeks of gestation (Carpenter and Coustan, 1982) and if they were previously normoglycemic. Pregnant women were systematically screened between 24 and 28 weeks of gestation with a fasting oral glucose tolerance test, in which venous blood was sampled 1 hour after oral loading with 100 g glucose (American Diabetes Association, 2004). Normal results were a blood glucose <95 $\mathrm{mg} / \mathrm{dL}$ at baseline, $<180 \mathrm{mg} / \mathrm{dL}$ at 1 hour, $<155 \mathrm{mg} / \mathrm{dL}$ at 2 hours and $<140 \mathrm{mg} / \mathrm{dL}$ at 3 hours. If diabetes was reported before pregnancy or an abnormal glucose test result was observed at the first prenatal visit (usually between 5 and 10 weeks of gestation), the women were considered to have a preexisting diabetes mellitus (this group included those with pregestational diabetes mellitus) and were included in the control group.

\subsection{Statistical analysis}

The odds ratio (OR) and 95\% confidence intervals (CI) for the association between outcomes and chlordecone were estimated using multiple logistic regression. Polytomous logistic regression was used to estimate simultaneously the risks of non-ordered hypertensive disorders of pregnancy $(\mathrm{GH}, \mathrm{PE})$ versus a common control group (without $\mathrm{GH}$ and without $\mathrm{PE})$. 
Regression models included the following potential confounders chosen a priori as being likely to interfere with the association between chlordecone exposure and outcome variables (see Table 1 and supplemental material, Table S1): maternal place of birth (Guadeloupe/Martinique, other Caribbean islands, Europe), place of enrolment (University hospital, local hospital, local antenatal care unit), maternal age $(\leq 25,26-31,32-37, \geq 38$ years), pre-pregnancy body mass index (BMI; in $\mathrm{kg} / \mathrm{m}^{2}$; underweight or normal: $<25$, overweight: $25-<30$, obese: $\geq 30$ ) and average weekly weight gain during pregnancy categorized according to the median (in g/week) $(<340, \geq 340)$. Because a substantial fraction of chlordecone is transported by lipids, all analyses were further adjusted for the total lipid concentration in maternal plasma (in g/L). Analyses were performed using chlordecone as a categorical variable (in quartiles, in $\mu \mathrm{g} / \mathrm{L}$ ) and as a $\log 10$-transformed continuous variable.

When chlordecone was analyzed as a categorical variable, exposure levels equal to or below the LOD were included in the first (lowest) quartile. In sensitivity analyses, we handled missing values for chlordecone $(\mathrm{N}=213)$ using multiple imputation techniques (Little and Rubin, 1986; Rubin, 2008) implemented in the R mi package (Su et al., 2011). For the imputation procedure, we included the following predictors of exposure categories: case status, maternal place of birth, place of enrolment, education level, parity, maternal age, marital status, pre-pregnancy BMI, and weight gain during pregnancy. A total of five imputed datasets were generated and the main analyses were repeated. Final estimators of associations were then combined using the SAS Proc MIANALYZE procedure.

When chlordecone was analyzed as a continuous variable, we imputed values of chlordecone plasma concentrations below the LOD (12.4\%) using the likelihood method (Jin et al., 2011), under the assumption that chlordecone concentration is log-normally distributed. When examining relations between outcomes and exposures considered as continuous 
variables, simple substitution methods replacing values <LOD by $0, \mathrm{LOD} / 2, \mathrm{LOD}$ or others, may lead to biased estimations when the percentage of non-detects is $>15 \%$ (Baccarelli et al., 2005; Whitcomb and Schisterman, 2008); consequently, the use of distribution-based multiple imputation is recommended (EPA, 2000). These methods have been shown to be able to produce unbiased estimations, even when the percentage of detected values is high (50\% to $70 \%)$. Five datasets with imputed concentrations below the LOD were generated and analyzed, and the five estimations of associations were then combined using the SAS Proc MIANALYZE procedure. To identify the linear and/or non-linear components of the relationship between chlordecone exposure and pregnancy outcomes, we examined spline functions (with three knots at the quartiles of the distribution), using the SAS macro developed by Desquilbet and Mariotti (2010).

SAS software version 9.3 (SAS Institute Inc., Cary, North Carolina) and R version 2.12.2 (http://www.r-project.org/) were used for analyses; all tests were two-sided, and P values $<0.05$ were considered statistically significant.

\section{Results}

The mean age of the 779 women included in the analysis was 31 years (range 12.4 to 49.6); $77.8 \%$ were born in Guadeloupe or Martinique, $69.2 \%$ were enrolled at the Guadeloupe university hospital, and $40 \%$ were classified as overweight or obese before pregnancy. Overall, $8.3 \%$ of all women had GH and 4\% PE. GDM was diagnosed in $9.1 \%$ of the women. Women with GH or GDM were more likely to be enrolled at the university hospital, to have been born on the other Caribbean islands, and to be older and obese (Table 1). Women with PE were more likely to be nulliparous, to have multi-foetal pregnancies and to have a greater weight gain during pregnancy. The proportion of women who smoked 
during their pregnancy was lower among those with either GH, PE or GDM. Chlordecone plasma concentration levels were above the LOD for $87.6 \%$ of the women and the median concentration was $0.4 \mu \mathrm{g} / \mathrm{L}$ (interquartile interval: 0.2-0.8).

Two hundred and eighty nine (27\%) of the 1068 women eligible for inclusion in the cohort were excluded, in most cases because of missing chlordecone exposure data $(\mathrm{N}=213)$. Excluded women were more likely than included women to have been born in the French West Indies or other Caribbean islands, to have a lower educational level and to have been enrolled at a local hospital. The frequencies of GH, PE and GDM among excluded women were $8.6 \%, 5.7 \%$ and $10.7 \%$, respectively (see supplemental material, Table S2).

Crude and adjusted ORs for hypertensive disorders during pregnancy in relation to exposure to chlordecone are given in Table 2. After adjustment for confounders, a negative association between chlordecone exposure and GH was detected: the decrease in OR was statistically significant for the third quartile $(\mathrm{OR}=0.2 ; 95 \%$ confidence interval $(\mathrm{CI}): 0.1,0.5)$ and fourth quartile $(\mathrm{OR}=0.3 ; 95 \% \mathrm{CI}: 0.2,0.6)$ of chlordecone plasma concentrations. When considering chlordecone as continuous variable, chlordecone concentration was significantly associated with a lower risk of $\mathrm{GH}(\mathrm{OR}=0.4 ; 95 \% \mathrm{CI}: 0.2,0.6)$. The study of the relationship between log-chlordecone blood concentrations and $\mathrm{GH}$ risk using splines revealed a significant decreasing linear component $(\mathrm{P}<0.01)$, the non-linear component not being significant $(\mathrm{P}=0.37)$ (see supplemental material, Figure $\mathrm{S} 1$ ). In contrast, we found no significant association between chlordecone exposure during pregnancy and PE (Table 2).

There was no statistically significant association between chlordecone exposure during pregnancy and risk of GDM in both crude and adjusted models, although a decreasing trend in risk with increasing plasma chlordecone concentration was observed (Table 3).

The comparison of the associations obtained when considering complete cases $(\mathrm{N}=779)$ (Tables 2 and 3) or all subjects with missing chlordecone values imputed $(\mathrm{N}=992)$ 
(supplemental material, Table S3) shows that imputation attenuated the slope of decreased risk of $\mathrm{GH}$, but the decreasing trend in risk remained statistically significant. For PE and GDM, the results were less sensitive to the inclusion of imputed values for missing chlordecone measurements.

In the subgroup of 358 women for whom DDE and PCB 153 concentrations were assayed, Spearman's rank correlation coefficients were $0.02(P=0.75)$ between chlordecone and DDE, and $-0.02(P=0.76)$ between chlordecone and PCB 153 . There is thus no evidence suggesting that DDE and PCB 153 are confounders in these associations.

\section{Discussion}

This study conducted in a population of pregnant women chronically exposed to chlordecone suggests an inverse association between chlordecone exposure during pregnancy and GH risk. Conversely, we found no statistically significant association between chlordecone exposure and PE or GDM.

These results were obtained by studying a population chronically exposed to chlordecone through the consumption of contaminated locally produced foodstuffs such as root vegetables. In the French West Indies, DDT has not been extensively used in agriculture or for disease vector control. In addition, this territory has had only very limited industrial activities involving significant use or emission of PCBs. Consequently, exposure to these chemical pollutants is likely to be the consequence of the universal atmospheric transport from remote areas and background contamination of the food chain. The poor correlation we found between chlordecone plasma concentration and other OCs chemicals may be explained by the different sources of exposure.

Chlordecone has not been measured in populations other than those in the French West Indies (Boucher et al., 2013; Dallaire et al., 2012; Guldner et al., 2010; Kadhel et al., 2014; 
Multigner et al., 2010) and Hopewell (Virginia, USA) (Cannon et al., 1978; Cohn et al., 1978). A chlordecone poisoning episode in Hopewell affected plant workers during the mid1970s. This led to a very high exposure, resulting in blood concentrations one hundred to one thousand times greater than those currently observed among the French West Indian population. Chlordecone exposure was also measured among adult residents of Hopewell during the mid-1970s and the serum concentrations in subjects with detectable values (at this time the LOD was around $1.5 \mu \mathrm{g} / \mathrm{L}$ ) was between 5 and $32 \mu \mathrm{g} / \mathrm{L}$ (Cannon et al., 1978), a range similar to those currently observed in French West Indies population.

Very few studies have been conducted in this domain. The major epidemiological studies that investigated the effects of pesticides on pregnancy-related hypertensive disorders and GDM examined the consequences of occupational or residential exposure to these agents. In these studies, pesticide exposure was frequently nonspecific, or the pesticides belonged to chemical families with particular properties, different from chlordecone (Nordby et al., 2006; Nugteren et al., 2012; Saldana et al., 2007, 2009; Willis et al., 1993). A recent report described the relationship between serum levels of persistent $\mathrm{OC}$ measured during the third trimester of pregnancy and the development of GH and PE, among 2,193 women included in a large birth cohort study in the United States (Savitz et al., 2013). The authors found an inverse association between exposure to DDE or PCBs, and GH and PE, and the association was stronger for PE. Other studies on the risk of hypertension were conducted in the general population exposed to OC pesticides, and report conflicting results (Goncharov et al., 2011; Ha et al., 2009; Valera et al., 2013a, 2013b). These studies represent a pathophysiological context different than hypertensive disorders of pregnancy. Thus, the body of evidence relevant to the association between OC pesticides and hypertensive disorders of pregnancy is limited, and therefore our findings should be interpreted with caution. 
There are several modes of action of chlordecone that could explain the inverse association with the risk of GH. Animal studies have shown that chlordecone exposure affects centrally regulated functions through noradrenaline-mediated effects (Chen et al, 1985; Tilson et al, 1987). Additional studies in rats have shown that chlordecone induces hypothermia mediated by alterations in alpha-adrenergic nervous system (Cook et al., 1987, 1988a, 1988b; Swanson and Wooley, 1982). Both the regulation of central body temperature and the control of vascular tone regulating blood pressure are under the influence of adrenergic mechanisms in the sympathetic arm of the autonomic nervous system. Unfortunately, blood pressure measurements were not reported in any of the studies cited above. It has not been established whether or not chlordecone acts on the regulation of blood pressure in the same way and direction as on the central temperature. Another possible mode of action is related to the endocrine disrupting properties of chlordecone with progestagenic-like characteristics. Chlordecone stimulates the synthesis of the progesterone receptor in rat uterine tissues in vivo (Hammond et al., 1979), and can inhibit the binding of the progestin agonist R5020 to the form A of the progesterone receptor in vitro (Vonier et al., 1996). Progesterone also has hypotensive properties (Rylance et al., 1985) and the progesterone receptor in vascular smooth muscle cells has been identified as a target (Falkenstein et al., 1996). These observations raise the possibility that the observed inverse association between exposure to chlordecone and risk of $\mathrm{GH}$ may be due to the sympathomimetic and/or progestin properties of chlordecone.

However, the possibility of reverse causation cannot be excluded: GH may affect the chlordecone concentration in blood. Indeed, during pregnancy there is a physiological increase in plasma volume (Letsky, 2008), and this could lead to a dilution of chlordecone in the plasma of pregnant women. Nevertheless, GH does not cause specific changes in plasma volume compared to normotensive pregnant women (Silver et al., 1998), and the mechanisms 
through which blood pressure may influence the chlordecone concentration in blood, if any, are unclear.

The possible influence of other, unknown, determinants that may be associated with both plasma chlordecone concentrations and GH should also be considered. Savitz et al. (2013) raised the possibility that renal dysfunction and/or hypertriglyceridemic dyslipidemia may distort the association observed between DDE or PCB exposure and GH or PE. However, this is not fully coherent with the fact that we found no significant association between chlordecone exposure during pregnancy and PE: both renal impairment and dyslipidemia are more likely in cases of PE than GH (Franz \& Wendler, 1992; Gallos et al, 2013; Wang et al, 2013).

The main strengths of this study lie in its design, a population-based cohort study, and the exposure and outcome measurements. Chlordecone exposure was determined with maternal plasma samples, providing an accurate reflection of the load of this compound in the body (Cohn et al., 1978; Guzelian, 1982). Its half-life in blood is around 6 months (Cohn et al., 1978), so a single measure at the end of pregnancy can be considered to be reasonably representative of exposure throughout the pregnancy. Co-exposures to other OC compounds were also considered (DDE and PCB153). Data for pregnancy complications were collected from obstetricians participating in the cohort study, which enhances their reliability. Also, the known risk factors for GH, PE or GDM were found. The small numbers in some of the groups may however have limited our capacity to uncover associations with PE in particular.

\section{Conclusion}

This study suggests a possible inverse association between chlordecone exposure during pregnancy and GH but no relationship with PE or GDM. Additional studies are necessary to 
explore the mechanisms involved, and in parallel to identify putative unknown confounding factors that may affect this association.

\section{Acknowledgments}

This study was made possible by the support of INSERM; Agence Nationale de la Recherche; Agence Française de Sécurité Sanitaire de l'Environnement et du Travail; Programme, National de Recherche sur les Perturbateurs Endocriniens; Direction Générale de la Santé; and Institut de Veille Sanitaire. All authors saw and approved the final manuscript. The authors declare no conflict of interests. Luc Multigner and Sylvaine Cordier contributed equally to this work.

\section{References}

American Diabetes Association. Gestational Diabetes Mellitus. Dia Care 2004; 27: s88-s90.

Baccarelli A, Pfeiffer R, Consonni D, Pesatori AC, Bonzini M, Patterson DG et al. Handling of dioxin measurement data in the presence of non-detectable values: overview of available methods and their application in the Seveso chloracne study. Chemosphere 2005; 60: 898906.

Cabidoche Y-M, Achard R, Cattan P, Clermont-Dauphin C, Massat F, Sansoulet J. Longterm pollution by chlordecone of tropical volcanic soils in the French West Indies: a simple leaching model accounts for current residue. Environ Pollut 2009; 157: 1697-705.

Carpenter MW, Coustan DR. Criteria for screening tests for gestational diabetes. Am J Obstet Gynecol 1982;144: 768-73. 
Cohn WJ, Boylan JJ, Blanke RV, Fariss MW, Howell JR, Guzelian PS. Treatment of chlordecone (Kepone) toxicity with cholestyramine. Results of a controlled clinical trial. N Engl J Med 1978; 298: 243-8.

Chen PH, Tilson HA, Marbury GD, Karoum F, Hong JS. Effect of chlordecone (Kepone) on the rat brain concentration of 3-methoxy-4-hydroxyphenylglycol: evidence for a possible involvement of the norepinephrine system in chlordecone-induced tremor. Toxicol Appl Pharmacol 1985;77: 158-64.

Cook LL, Gordon CJ, Tilson HA, Edens FW. Chlordecone-induced effects on thermoregulatory processes in the rat. Toxicol Appl Pharmacol 1987; 90: 126-34.

Cook LL, Edens FW, Tilson HA. Possible brainstem involvement in the modification of thermoregulatory processes by chlordecone in rats. Neuropharmacology 1988a; 27: 871-9.

Cook LL, Edens FW, Tilson HA. Pharmacological evaluation of central adrenergic involvement in chlordecone-induced hypothermia. Neuropharmacology 1988b; 27: 881-7.

Das S, Thomas P. Pesticides interfere with the nongenomic action of a progestogen on meiotic maturation by binding to its plasma membrane receptor on fish oocytes. Endocrinology 1999; 140: 1953-6. 
Debier C, Pomeroy P, Dupont C, Joiris C, Comblin V, Le Boulengé E, et al. Quantitative dynamics of PCB transfer from mother to pup during lactation in UK grey seals Halichoerus grypus. Mar Ecol Prog Ser 2003; 247: 237-48.

Desquilbet L, Mariotti F. Dose-response analyses using restricted cubic spline functions in public health research. Stat Med 2010; 29: 1037-57.

Dubuisson C, Héraud F, Leblanc JC, Gallotti S, Flamand C, et al. Impact of subsistence production on the management options to reduce the food exposure of the Martinican population to Chlordecone. Regul Toxicol Pharmacol; 2007; 49: 5-16

EPA US. Guidance for data quality assessment. Practical methods for data analysis. Office of Environmental Information, EPA QA/G-9, QA00 Version Washington, DC, 2000. Available http://www.epa.gov/region6/qa/qadevtools/mod4references/secondaryguidance/g9-final.pdf [Accessed 19 March 2014].

EUROCAT. 2005. Guide 1.3 and reference documents. Instructions for the registration and surveillance of congenital anomalies. Available: http://www.eurocatnetwork.eu/aboutus/publications/publications [Accessed 19 September 2013].

Falkenstein E, Meyer C, Eisen C, Scriba PC, Wehling M. Full-length cDNA sequence of a progesterone membrane-binding protein from porcine vascular smooth muscle cells. Biochem Biophys Res Commun 1996; 229: 86-9. 
Faroon O, Kueberuwa S, Smith L, DeRosa C. ATSDR evaluation of health effects of chemicals. II. Mirex and chlordecone: health effects, toxicokinetics, human exposure, and environmental fate. Toxicol Ind Health 1995; 11: 1-203.

Franz, H., Wendler, D. A controlled study of maternal serum concentrations of lipoproteins in pregnancy-induced hypertension Arch Gynecol Obstet 1992; 252: 81-86

Gallos ID, Sivakumar K, Kilby MD, Coomarasamy A, Thangaratinam S, Vatish M. Preeclampsia is associated with, and preceded by, hypertriglyceridaemia: a meta-analysis. BJOG. 2013; 120:1321-32.

Goncharov A, Pavuk M, Foushee HR, Carpenter DO. Blood pressure in relation to concentrations of PCB congeners and chlorinated pesticides. Environ Health Perspect 2011; 119: 319-25.

Guldner L, Multigner L, Héraud F, Monfort C, Thomé JP, Giusti A, et al. Pesticide exposure of pregnant women in Guadeloupe: ability of a food frequency questionnaire to estimate blood concentration of chlordecone. Environ Res 2010; 110:146-51.

Guzelian PS. Comparative toxicology of chlordecone (Kepone) in humans and experimental animals. Annu Rev Pharmacol Toxicol 1982; 22: 89-113.

Ha MH, Lee DH, Son HK, Park SK, Jacobs DR Jr. Association between serum concentrations of persistent organic pollutants and prevalence of newly diagnosed 
hypertension: results from the National Health and Nutrition Examination Survey 1999-2002. J Hum Hypertens 2009; 23: 274-86.

Hammond B, Katzenellenbogen BS, Krauthammer N, McConnell J. Estrogenic activity of the insecticide chlordecone (Kepone) and interaction with uterine estrogen receptors. Proc Natl Acad Sci USA 1979; 76: 6641-45.

Hsu YN, Lin MT, Hong JS, Tsai MC. Effect of chlordecone exposure on thermoregulation in the rat. Pharmacology 1986; 32: 292-300.

Jin Y, Hein MJ, Deddens JA, Hines CJ. Analysis of lognormally distributed exposure data with repeated measures and values below the limit of detection using SAS. Ann Occup Hyg 2011; 55: 97-112.

Kadhel P, Monfort C, Coste N; Rouget F, Thomé JP, Multigner L, et al. Chlordecone exposure, length of gestation and risk of preterm birth. Am J Epidemiol 2014; Jan 8. [Epub ahead of print].

Lee D-H, Lee I-K, Song K, Steffes M, Toscano W, Baker BA, et al. A strong dose-response relation between serum concentrations of persistent organic pollutants and diabetes: results from the National Health and Examination Survey 1999-2002. Diabetes Care 2006; 29: $1638-44$.

Leeman L, Fontaine P. Hypertensive disorders of pregnancy. Am Fam Physician 2008; 78: 93-100. 
Letsky EA. 2008. Blood Volume, Haematinics, Anaemia. In: Medical Disorders in Obstetric Practice (M. de Swiet Ed), Blackwell Science Ltd, 29-60.

Little RJA, Rubin DB. 1986. Statistical analysis with missing data. John Wiley \&amp; Sons, Inc., New York, NY, USA.

Montgomery MP, Kamel F, Saldana TM, Alavanja MCR, Sandler DP. Incident diabetes and pesticide exposure among licensed pesticide applicators: Agricultural Health Study, 19932003. Am J Epidemiol 2008; 167: 1235-46.

Multigner L, Ndong JR, Giusti A, Romana M, Delacroix-Maillard H, Cordier S, et al. Chlordecone exposure and risk of prostate cancer. J Clin Oncol 2010; 28: 3457-62.

National High Blood Pressure Education Program. Report of the Working Group on High Blood Pressure in Pregnancy. Am J Obstet Gynecol. 2000; 183: S1-S22.

Nordby K-C, Irgens LM, Kristensen P. Immunological exposures in Norwegian agriculture and pre-eclampsia. Paediatr Perinat Epidemiol 2006; 20: 462-70.

Nugteren JJ, Snijder CA, Hofman A, Jaddoe VWV, Steegers EAP, Burdorf A. Work-related maternal risk factors and the risk of pregnancy induced hypertension and preeclampsia during pregnancy. The Generation R Study. Plos One 2012; 7: e39263. 
Olsen J, Basso O. Reproductive Epidemiology. 2005. In: Handbook of Epidemiology (Ahrens W, Pigeot I eds, Berlin: Springer, pp 1045 -95.

Rubin DB. 2008. Frontmatter. In: Multiple Imputation for Nonresponse in Surveys, John Wiley \& Sons, Inc, i-xxix.

Rylance PB, Brincat M, Lafferty K, Trafford JC De, Brincat S, Parsons V, et al. Natural progesterone and antihypertensive action. Br Med J Clin Res 1985;290: $13-4$.

Rylander L, Rignell-Hydbom A, Hagmar L. A cross-sectional study of the association between persistent organochlorine pollutants and diabetes. Environ Health 2005; 4: 28.

Saldana TM, Basso O, Baird DD, Hoppin JA, Weinberg CR, Blair A, et al. Pesticide exposure and hypertensive disorders during pregnancy. Environ Health Perspect 2009; 117: 1393-6.

Saldana TM, Basso O, Hoppin JA, Baird DD, Knott C, Blair A, et al. Pesticide exposure and self-reported gestational diabetes mellitus in the Agricultural Health Study. Diabetes Care 2007; 30: 529-34.

Savitz D, Gregory A Wellenius, Klebanoff M, Jensen E, Longnecker M. Persistent Organochlorines and Hypertensive Disorders of Pregnancy. Environment and Health Bridging South, North, East and West Conferences. 2013 Available: http://ehp.niehs.nih.gov/ehbasel13/o-4-26-04 [Accessed 30 October 2013]. 
Sibai B, Dekker G, Kupferminc M. Pre-eclampsia. Lancet 2005; 365: 785-99.

Silver HM, Seebeck M, Carlson R. Comparison of total blood volume in normal, preeclamptic, and nonproteinuric gestational hypertensive pregnancy by simultaneous measurement of red blood cell and plasma volumes. Am J Obstet Gynecol 1998; 179: 87-93.

Swanson KL, Woolley DE. Comparison of the neurotoxic effects of chlordecone and dieldrin in the rat. Neurotoxicology 1982; 3: 81-102.

Tilson HA, Hong JS, Gerhart JM, Walsh TJ. 1987. Animal models in neurotoxicology: The neurobehavioral effects of chlordecone (Kepone). Thompson T, Dews PB, Barrett JE (Eds), Neurobehavioral pharmacology, Lawrence Erlbaum Assoc, Hillsdale, NJ 1987: 249-273

Valera B, Ayotte P, Poirier P, Dewailly E. Associations between plasma persistent organic pollutant levels and blood pressure in Inuit adults from Nunavik. Environ. Int 2013a; 59: $282-9$.

Valera B, Jørgensen ME, Jeppesen C, Bjerregaard P. Exposure to persistent organic pollutants and risk of hypertension among Inuit from Greenland. Environ Res 2013b; 122: $65-73$.

Vonier PM, Crain DA, McLachlan JA, Guillette LJ Jr, Arnold SF. Interaction of environmental chemicals with the estrogen and progesterone receptors from the oviduct of the American alligator. Environ Health Perspect 1996; 104: 1318-22. 
Wang IK, Muo CH, Chang YC, Liang CC, Chang CT, Lin SY, et al. Association between hypertensive disorders during pregnancy and end-stage renal disease: a population-based study. CMAJ. 2013; 185:207-13.

Whitcomb BW, Schisterman EF. Assays with lower detection limits: implications for epidemiological investigations. Paediatr Perinat Epidemiol 2008; 22: 597-602.

Willis WO, De Peyster A, Molgaard CA, Walker C, MacKendrick T. Pregnancy outcome among women exposed to pesticides through work or residence in an agricultural area. $\mathbf{J}$ Occup Med 1993; 35: 943-49.

Yu-Sung S, Gelman A, Hill J, Yajima M. Multiple Imputation with Diagnostics (mi) in R: Opening Windows into the Black Box. J Stat Softw 2011; 45:1-31

Zhang C, Ning Y. Effect of dietary and lifestyle factors on the risk of gestational diabetes: review of epidemiologic evidence. Am J Clin Nutr 2011; 94:1975S-1979S. 